\title{
Natural Gas - Electric Interface Study
}

Brian Sergi, Omar J. Guerra, Michael Craig, Kwabena Addo Pambour, Carlo Brancucci, and Bri-Mathias Hodge

Thursday 19 August 2020 


\section{Outline}

Motivation

Overview of existing and proposed approaches

Executive summary

Description of the proposed coordination framework

Case study: Colorado's electricity and natural gas system 


\section{The Importance of Coordinated Electricity and Natural Gas Systems}

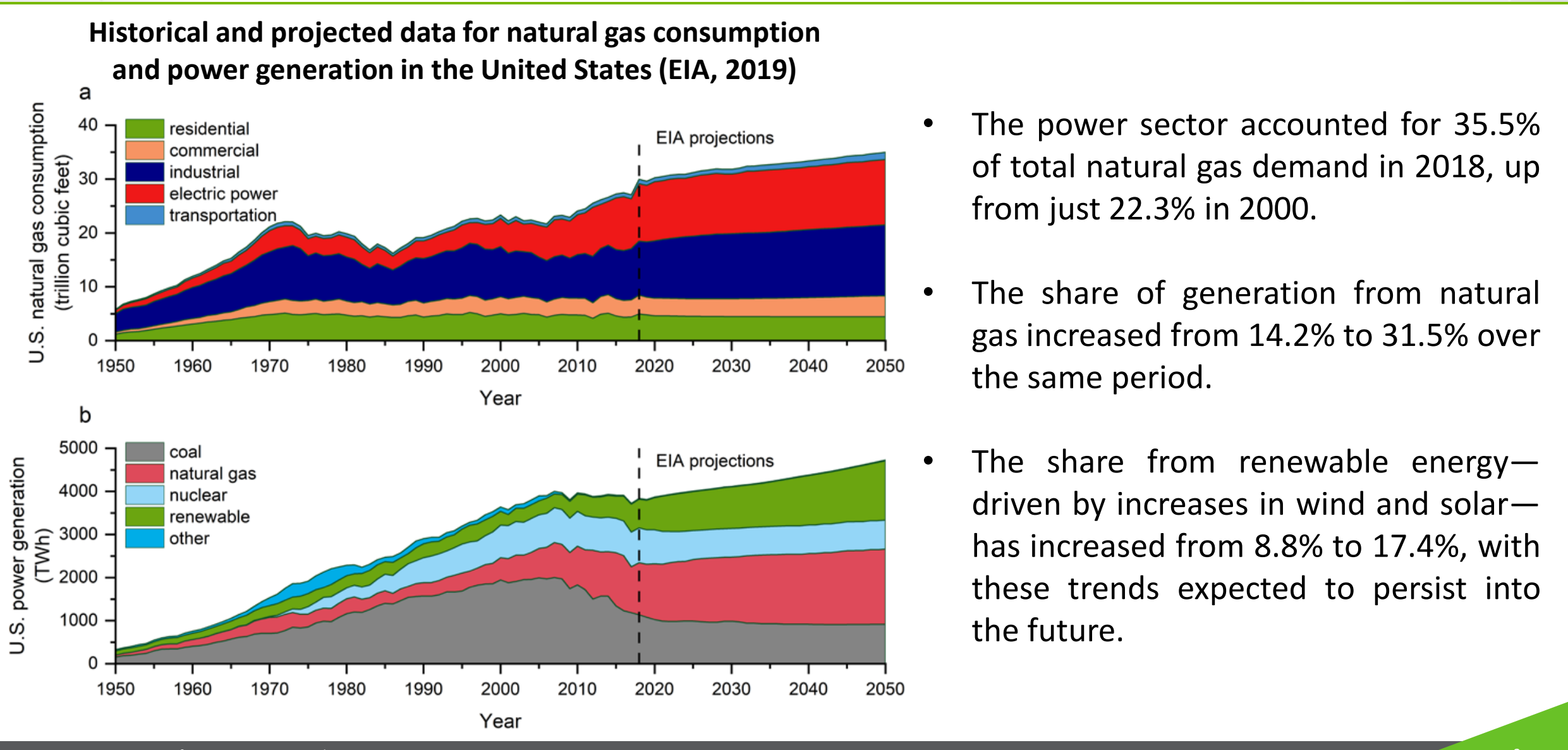




\section{Rising interdependence may result in reliability issues}

\section{Northeast Power Coordinating Council}

NPCC: Cumulative Impact of Outage Type vs Temperature (F)

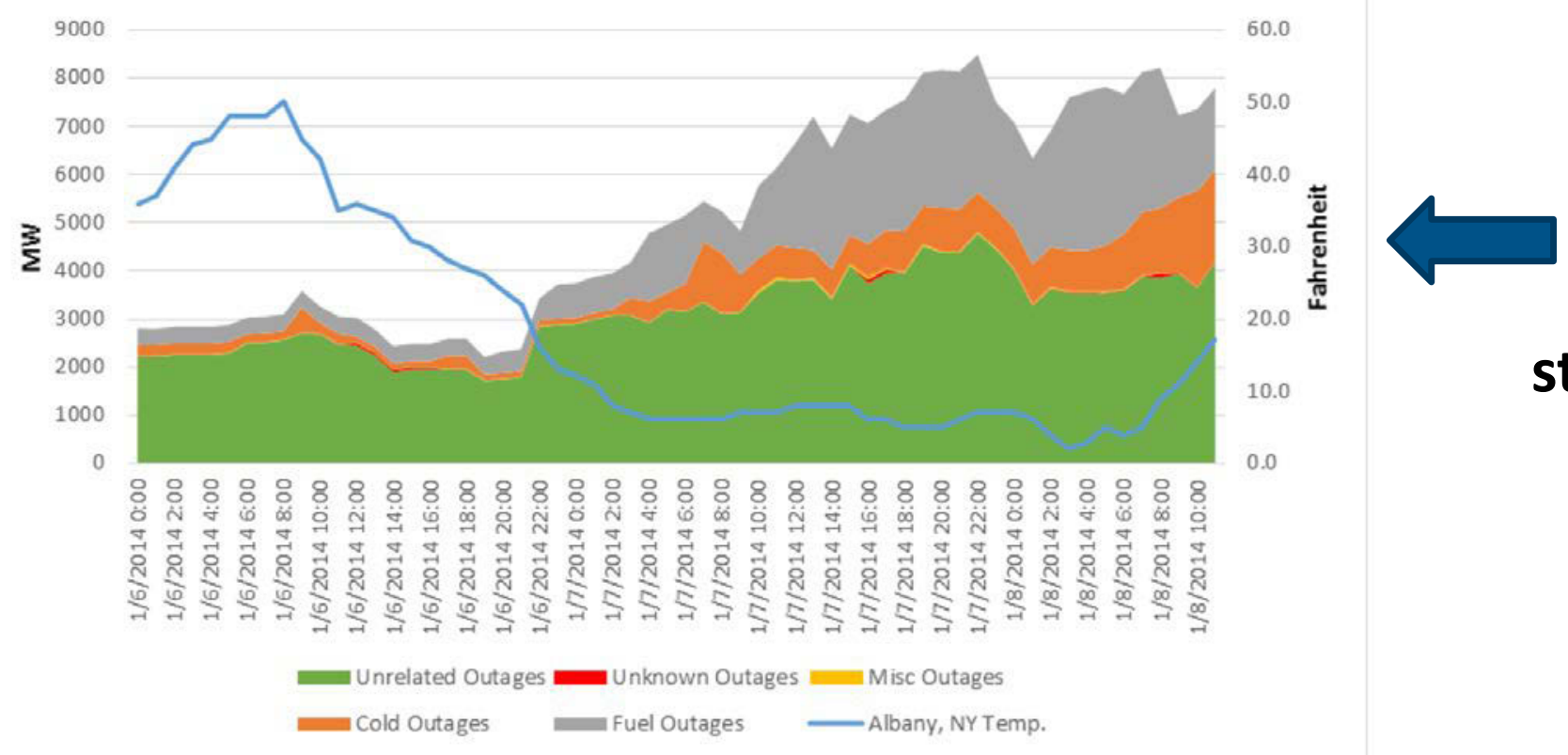

2014 "Polar Vortex" resulted in large gas outages due to fuel starvation at generators with interruptible contracts 
Overview of approaches for coordination between electricity and natural gas systems

\section{Decision making level}

- Planning: Optimize the location, capacity, and timing of investment decisions associated with generation or production, transmission, and storage assets in an integrated system.

- Operation: Improve reliability and minimize the operational costs associated with natural gas and electricity supply, natural gas supply contracts, and load shedding or unserved natural gas.

\section{Coordination strategy}

- Central-planning: The operation of the two systems is optimized simultaneously.

- Market-based: The two systems are optimized or simulated separately, with coordination occurring via the exchange of information such as prices, gas demand from generators, gas availability from the gas network, etc.

\section{Policy and regulation}

- FERC Order 809: Among other changes, includes a third intra-day market for scheduling natural gas deliveries.

- Shaped flow: Time-variant gas nominations at the day-ahead and intra-day market.
Our approach:

- Operation focus

- Market-based coordination

- Includes FERC Order 809

- Includes the analysis of shaped flows 
Executive summary: brief discussion of the three studies carried out in this project

\section{Development of modeling platform for coordination of natural and electricity systems}

- Development of the modeling platform for coordination of interdependence of natural gas and electricity systems

- Assessment of the value of day-ahead coordination of power and natural gas grid operations based on a test system
Assessment of the value of intraday coordination of natural gas and electricity systems
- Modeling of the U.S. Federal Energy Regulatory Commission (FERC) Order 809, issued in 2015 to improve day-ahead and intraday coordination of power and gas systems

- Quantification of the value of improved intraday coordination between gas and electric power systems based on a test system

\section{Evaluation of market-based} coordination of electricity and natural gas system operations
- Modeling of coordination of natural gas and electricity systems across day-ahead (DA), intra-day (ID), and real-time (RT) markets

- Assessment of coordination from DA to RT markets, including different levels of renewable penetration and the use of shaped flow nominations, based on Colorado power and gas grids

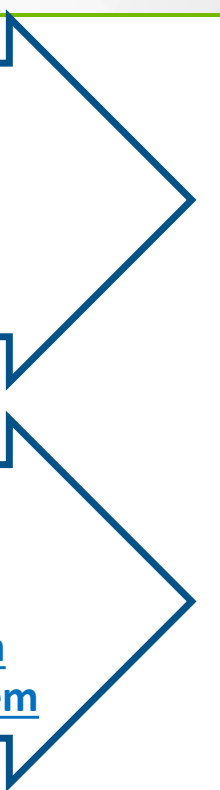


Development of modeling platform for coordination of natural and electricity systems (Key findings)

\section{Development of modeling} platform for coordination of natural and electricity systems
- Development of the modeling platform for coordination of interdependence of natural gas and electricity systems

- Assessment of the value of day-ahead coordination of power and natural gas grid operations based on a test system

- Day-ahead coordination contributes to a reduction in curtailed gas in high-stress periods (such as those with large ramps in gas offtakes) and a reduction in energy consumption of gas compressor stations.

- In high renewable systems that rely on gas ramping to balance variability in wind and solar, such improvements are likely to enhance the overall reliability of the power system.

Link to the publication: https://www.mdpi.com/1996-1073/11/7/1628 
Assessment of the value of intraday coordination of natural gas and electricity systems (Key findings)

Assessment of the value of intraday coordination of natural gas and electricity systems

- Modeling of the U.S. Federal Energy Regulatory Commission (FERC) Order 809, issued in 2015 to improve day-ahead and intraday coordination of power and gas systems

- Quantification of the value of improved intraday coordination between gas and electric power systems based on a test system

- Intraday coordination reduces total power system production costs and natural gas deliverability constraints, yielding cost and reliability benefits.

- Improved intraday variable renewable energy forecasts and higher variable renewable energy capacities increase intraday coordination benefits for gas network congestion.

Link to the publication: https://www.sciencedirect.com/science/article/pii/S0301421520302214 
Evaluation of market-based coordination of electricity and natural gas system operations (Key findings)

\section{Evaluation of market-based} coordination of electricity and natural gas system operations
- Modeling of coordination of natural gas and electricity systems across day-ahead (DA), intra-day (ID), and real-time (RT) markets

- Assessment of coordination from DA to RT markets, including different levels of renewable penetration and the use of shaped flow nominations, based on Colorado power and gas grids

- Coordination generally improves total gas delivery, which reduces out-of-merit order dispatch in the electricity system, and that such coordination can be useful under a range of operating conditions and renewable penetrations.

- Shaped flows stand to be a valuable tool for reducing unserved gas, particularly in systems with higher penetrations of wind and solar energy sources.

This study will be described in detail in the next slides 


\section{Systems}

\section{Electricity and natural gas systems coordination framework} (implemented in Python)

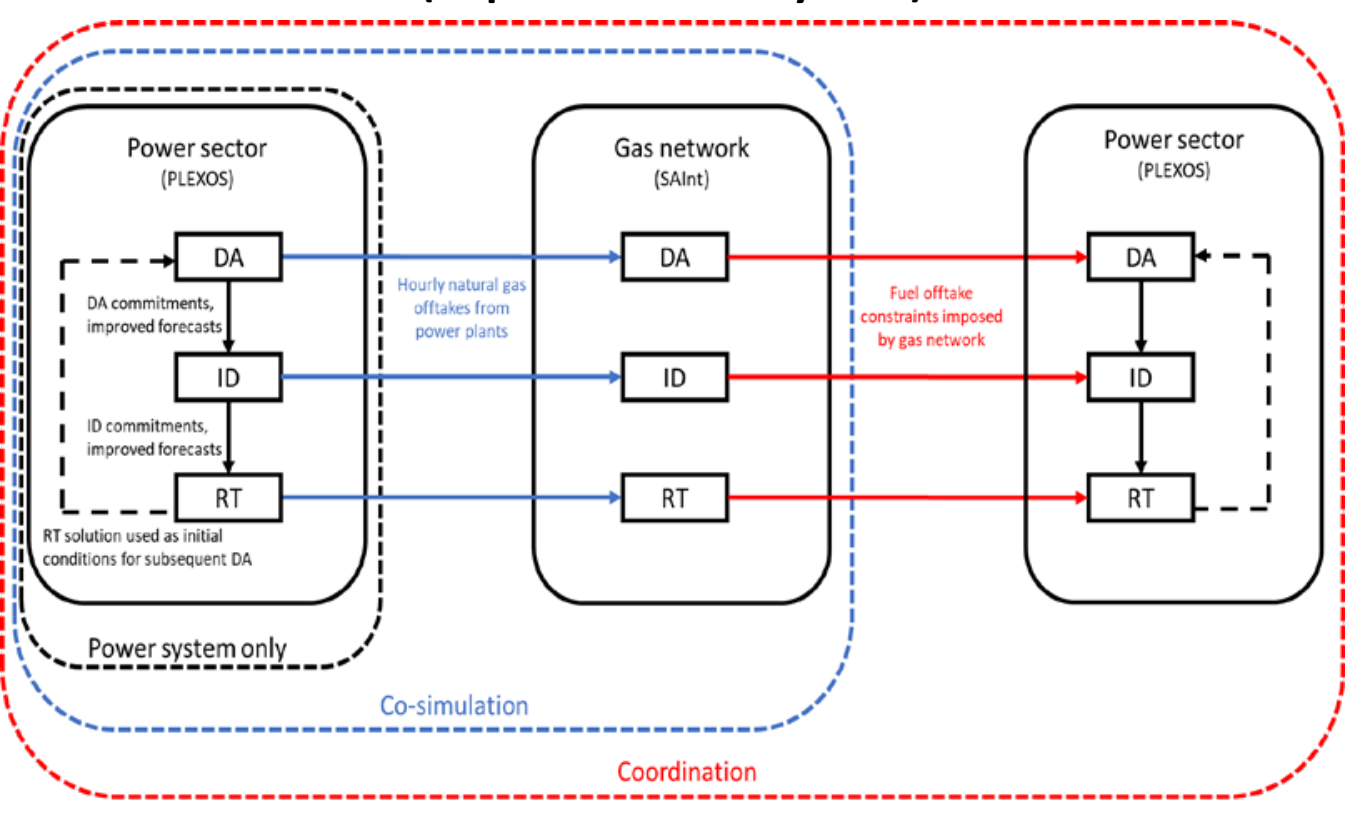

DA: day-ahead market, ID: intra-day market, and RT: real-time market
- Power system only: results from the first iteration of the power system model, before any communication with the gas network.

- Co-simulation: results after simulating gas offtakes from the power system model in the gas network; reflects curtailed gas but has not yet reoptimized the power system in response to gas constraints.

- Coordination: results after re-optimizing the power system with constraints from the gas simulation. 


\section{Case study: Colorado's electricity and natural gas systems}

Colorado's annual generation (left) and capacity mix (right) (PLEXOS was used to optimize power system operations in the DA, ID, and RT markets )

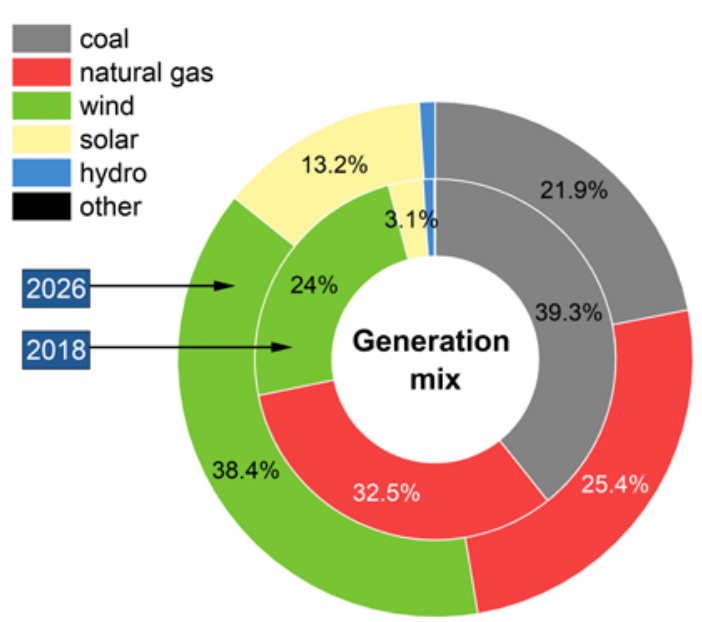

\begin{tabular}{lcc}
\hline Technology & $\begin{array}{c}\mathbf{2 0 1 8} \\
\text { (GW) }\end{array}$ & $\begin{array}{c}\mathbf{2 0 2 6} \\
\text { (GW) }\end{array}$ \\
\hline Coal & 3.88 & 2.42 \\
\hline Gas & \multicolumn{2}{c}{7.58} \\
\hline Wind & 6.02 & 9.81 \\
\hline Solar & 2.25 & 9.88 \\
\hline Hydropower & \multicolumn{2}{c}{0.73} \\
\hline Other & \multicolumn{2}{c}{1.5} \\
\hline
\end{tabular}

The 2018 fleet is based on current Colorado fleet, benchmarked to actual generation levels; the 2026 fleet is based on plans developed by Western Resource Advocates to meet Xcel targets:

https://westernresourceadvocates.org/blog/colorado-energy-planexplained/
Representation of the gas network. Based on data of the Front Range gas network in Colorado.

(SAInt was used to perform a transient hydraulic simulation of the operation of the natural gas system)



The offtake nodes include gas generators representing about $70 \%$ of the natural gas generator offtakes in the power system model, as well as information on demand profile for local distribution companies (LDCs).

The capacity of the Front Range pipeline system is largely paid for by the electric generators, and thus represents a system with sufficient firm capacity to serve the gas needs of these generators in most instances. 


\section{Power system characteristics}

\section{Total load, peak load, and peak net load for selected weeks}



\section{Share of renewable energy}

- Max penetration

Total generation share



Selected weeks for each season: Highest natural gas demand from the power sector, these weeks are likely to be the times when coordination between the two systems is critical (June 2-8 (spring), July 14-20 (summer), November 17-23 (fall), and December 12-18 (winter)). 


\section{Ramping requirements and gas nominations}

\section{Largest up and down ramps in net load (MW) in 2018 and} 2026;

$\square 2018 \square 2026$

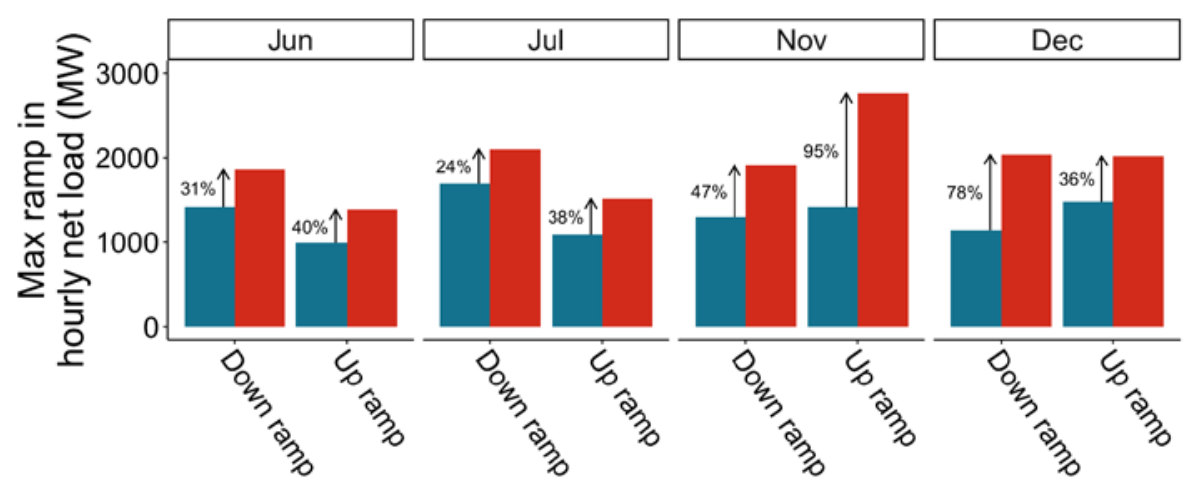

- Selected weeks for each season: Highest natural gas demand from the power sector, these weeks are likely to be the times when coordination between the two systems is critical (June 2-8 (spring), July 14-20 (summer), November 17-23 (fall), and December 12-18 (winter).

- Higher penetration of renewables in 2026 results in greater ramping requirements.

- Higher ramping requirements could be better accommodated when the operation of the two systems is coordinated.

\section{Ratable flow (current practice) and Shaped flow (proposed practice)}

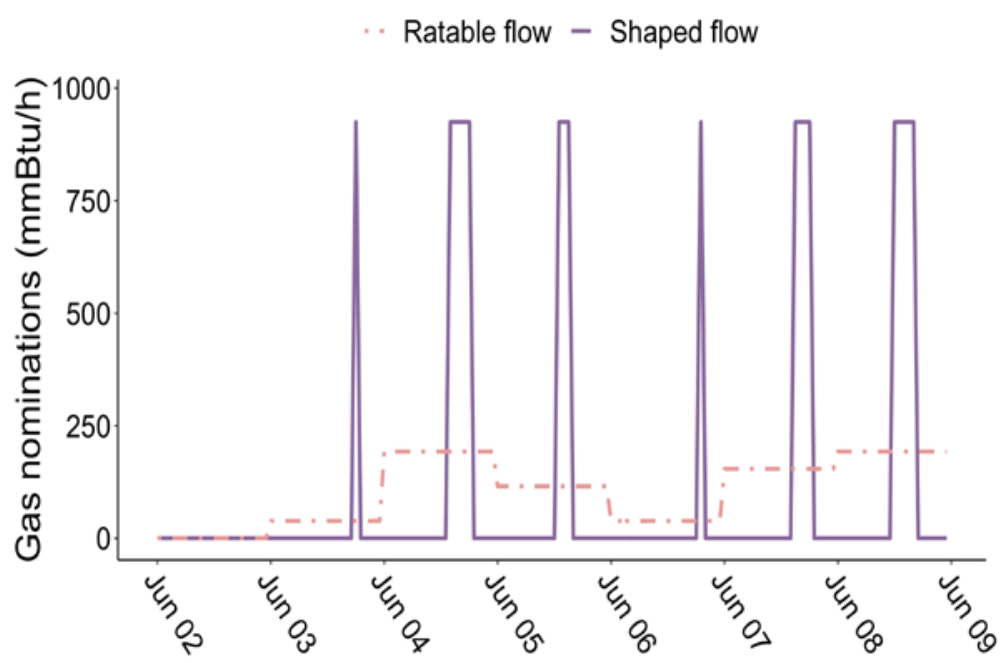

Hourly natural gas nominations from a single combustion turbine during the June week when using ratable gas nominations-in which nominations are the average of hourly gas offtakes over 24 hours-and shaped flow nominations -in which nominations are allowed to vary by hour. 


\section{Real-time dispatch (June scenario)}

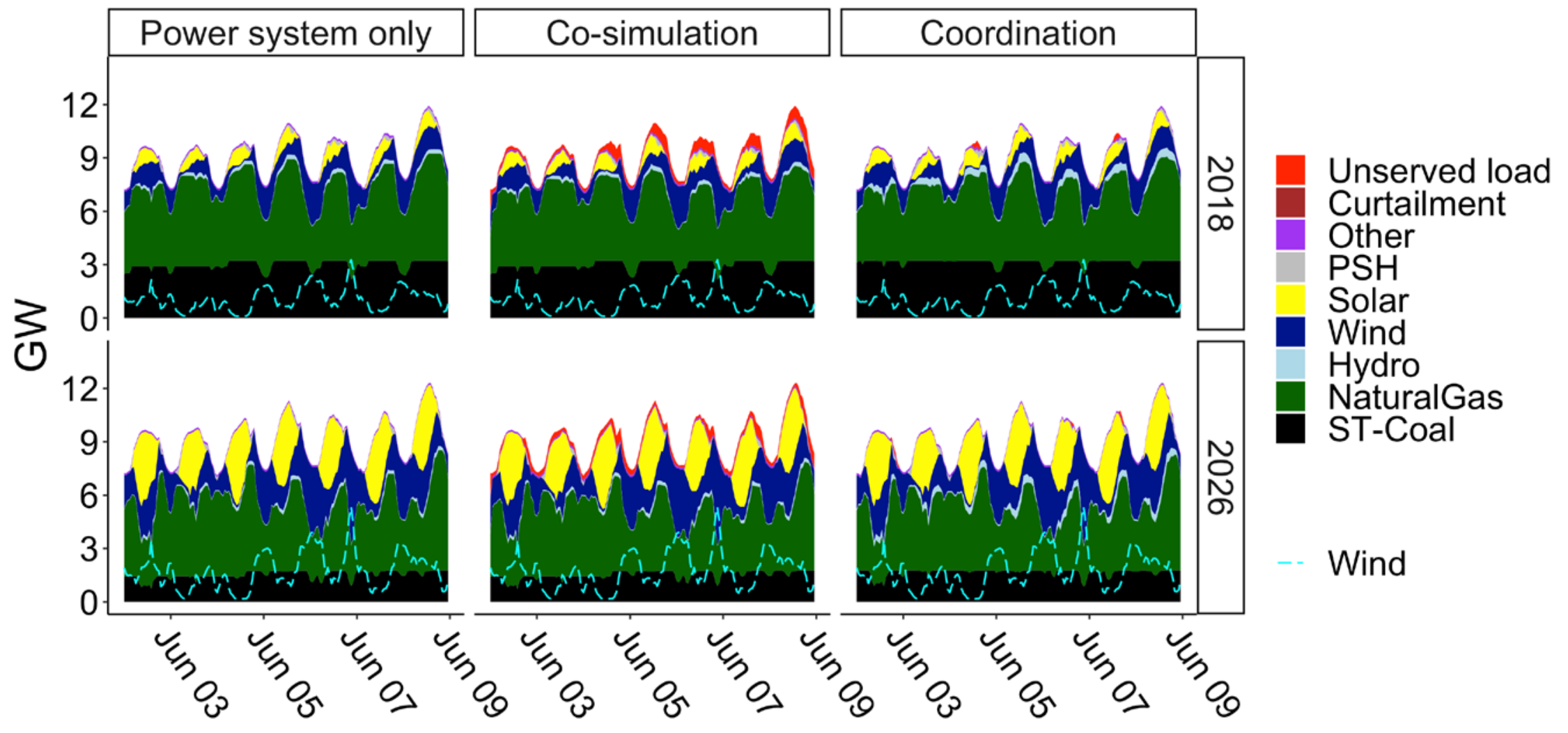


Gas offtakes from the gas network (RT, co-simulation level)

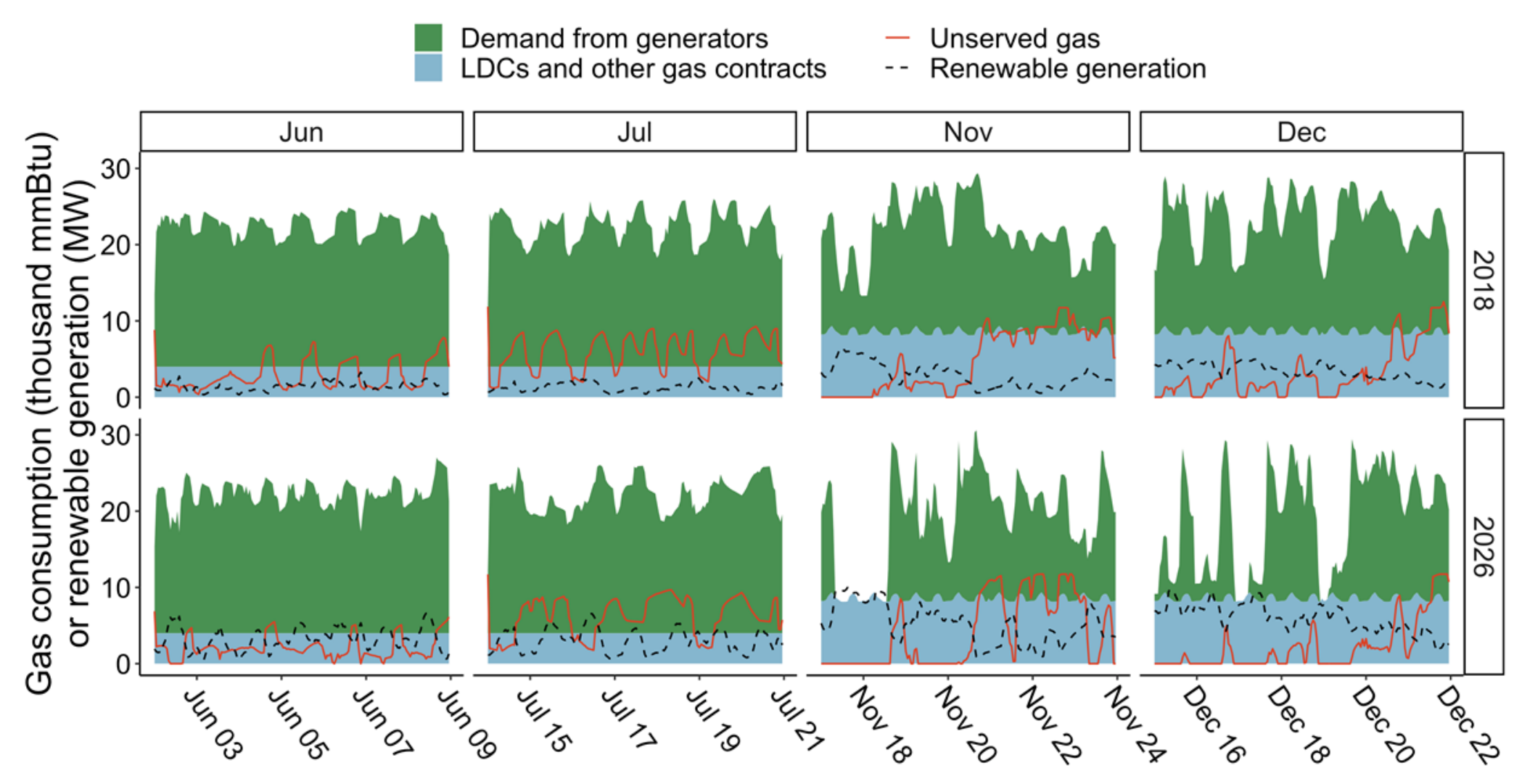




\section{Impacts of coordination on unserved load}

\section{Total unserved load}

(Numbers indicate unserved load as a percentage of total load that week).

- Power system only — Co-simulation $\square$ Coordination



- No unserved load in the initial power system optimization (power system only); however, when gas curtailments are imposed from constraints in the gas network (co-simulation), large amounts of unserved load occur.

- If the power system is re-optimized based on input from the gas network (coordination), the amount of gas curtailment and unserved load is substantially reduced. 


\section{Total real-time gas offtakes by node}






\section{Impacts of coordination and gas nominations on unserved gas}

Total unserved natural gas by week for the co-simulation and coordination scenarios (based on ratable flows)


scenario

Co-simulation Coordination
Total unserved natural gas using constant flows at the DA and ID market levels (ratable) and using hourly gas offtakes from generators (shaped flow)


Shaped flow scenario

Ratable flow Shaped flow
- Redispatch of the power sector based on constraints from the gas model (i.e. coordination) serves to reduce unserved gas by upwards of $97 \%$ relative to co-simulation.
- Shape flow gas nominations reduce curtailed gas offtakes when compared with ratable gas nominations 


\section{Conclusions}

- For the Colorado system, coordination greatly reduces the amount of curtailed gas generation without substantial cost increases, particularly in high electricity demand time periods (e.g. summer).

- The introduction of coordinated intra-day markets (as proposed by FERC Order 809) reduces unserved natural gas by almost $97 \%$ relative to uncoordinated operations for the Colorado system.

- The unavailability of gas for power generation can be caused by different factors; in periods of high electricity demand it may be driven by total delivery constraints, whereas in periods with high ramping requirements, it may be a function of constraints at the natural gas compressors.

- Moving from constant (i.e. ratable) flow to nominations that can vary by hour (i.e. shaped flow) in the day-ahead market can reduce curtailed gas offtakes, particularly for systems with larger penetrations of renewable generation. 


\section{Real-time dispatch (July scenario)}






\section{Real-time dispatch (November scenario)}




Real-time dispatch (December scenario)






\section{Thank you}

\section{NREL/PR-6A50-77699}

This work was authored by the National Renewable Energy Laboratory, operated by Alliance for Sustainable Energy, LLC, for the U.S. Department of Energy (DOE) under Contract No. DE-AC36-08GO28308. Funding provided by the Joint Institute for Strategic Energy Analysis (JISEA). The views expressed in the article do not necessarily represent the views of the DOE or the U.S. Government. The U.S. Government retains and the publisher, by accepting the article for publication, acknowledges that the U.S. Government retains a nonexclusive, paid-up, irrevocable, worldwide license to publish or reproduce the published form of this work, or allow others to do so, for U.S. Government purposes.

\section{JISEA}

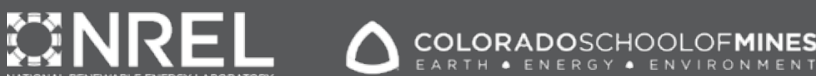

(2) COLORADO STATE



Massachusetts Institute of Technology
STA N F O R D UNIVERSITY
T. University of Colorado Boulder 